\title{
Graphite Furnace Atomic Absorption Spectrometric Determination of Bismuth(III) after Coprecipitation with Hafnium Hydroxide
}

\author{
Joichi UEDA and Midori TAKAGI* \\ Department of Chemistry, Faculty of Education, Kanazawa University, Marunouchi, Kanazawa 920 \\ (Received March 30, 1989)
}

\begin{abstract}
A method for the coprecipitation of bismuth(III) with hafnium hydroxide followed by a graphite-furnace atomic absorption spectrometric determination is described. Hafnium hydroxide coprecipitates quantitatively $0.05-3 \mu \mathrm{g}$ of bismuth(III) from $50-400 \mathrm{~cm}^{3}$ of sample solution at $\mathrm{pH} 5.8-11.2$. The presence of $2.5-50 \mathrm{mg}$ of hafnium in $25 \mathrm{~cm}^{3}$ does not affect the atomic absorbance of bismuth(III). The calibration curve is linear for $0.05-3 \mu \mathrm{g}$ of bismuth(III) in $25 \mathrm{~cm}^{3}$ and passes through the origin. Interference from the presence of large amounts of silver can be eliminated by removing silver as the ammine complex produced by the coprecipitation procedure at above $\mathrm{pH} 11$ with aqueous ammonia. Several other matrix ions investigated do not interfere with the determination in at least a 500 -fold mass ratio to bismuth(III). This method was successfully applied to the determination of trace bismuth(III) in commercial metal silver (purity: 99.99\%), and is also applicable to the determination of trace amounts of bismuth(III) in water sample.
\end{abstract}

Recently, bismuth(III) has been widely used in various materials such as medicaments, superalloys, or semiconductors and has increasingly been recognized to be important as a rare metal. Under these circumstances, the need for a trace analysis of bismuth(III) has also increased, and its preliminary enrichment has sometimes been required for extending the detection limit and for the separation of bismuth(III) from a sample matrix. The coprecipitation method is one of the most useful enrichment techniques, and several coprecipitants for bismuth(III $)^{1-13)}$ have been proposed.

Up until now we have been examining hafnium hydroxide as a new coprecipitant and have suggested that hafnium hydroxide is an effective coprecipitant for concentration prior to the trace analyses of cadmium, ${ }^{14)}$ copper, ${ }^{15)}$ beryllium, ${ }^{16)}$ gallium, ${ }^{17)}$ indium, ${ }^{17)}$ and $\operatorname{tin}^{18)}$ by the graphite-furnace atomic absorption spectrometry because it has a good collecting ability for these ions and coprecipitates few matrix ions, such as alkali and alkaline earth metals. We have found that hafnium hydroxide is also an excellent collector of trace amounts of bismuth(III) and that the coprecipitated bismuth(III) can be determined satisfactorily by graphite-furnace atomic absorption spectrometry. The method proposed here is simple and reproducible, and is available for the determination of trace amounts of bismuth(III) in metal silver and in water samples.

For the determination of bismuth(III) in metal silver, some coprecipitants such as hydroxides of iron(III), ${ }^{6-9)}$ aluminum, ${ }^{10,11)}$ and zirconium ${ }^{2)}$ have been proposed, but no coprecipitation methods have been used prior to the determination by the graphitefurnace atomic absorption spectrometry. For bismuth(III) in a water sample, only zirconium hydroxide ${ }^{1)}$ has been used for a determination by graphite-furnace atomic absorption spectrometry. Furthermore, each of these coprecipitants has its own disadvantages. For example, iron(III) hydroxide ${ }^{19,20)}$ is apt to copre- cipitate fairly large quantities of alkali and alkaline earth metals which may interfere with the determination. Though zirconium hydroxide ${ }^{21)}$ is a good coprecipitant, it is dissolved in acid slowly. In the case of aluminum hydroxide, ${ }^{10}$ ) the determination of bismuth(III) in silver is complicated, because the recovery of bismuth(III) is seriously decreased with a rise in $\mathrm{pH}$ by the addition of aqueous ammonia to remove silver as an ammine complex. The use of hafnium hydroxide overcomes these disadvantages.

This paper describes the fundamental conditions for the coprecipitation of bismuth(III) with hafnium hydroxide and for a graphite furnace atomic absorption spectrometric determination of bismuth(III).

\section{Experimental}

Apparatus. A Hitachi 170-70 Zeeman-effect atomic absorption spectrometer with a Hitachi bismuth(III) hollowcathode lamp was used for the atomic absorption spectrometric measurements and a Hitachi-Horiba Model M-5 glass electrode $\mathrm{pH}$ meter was used for the $\mathrm{pH}$ measurements.

Reagents. Standard Bismuth(III) Solution: A solution containing about $1 \mathrm{mg} \mathrm{cm}^{-3}$ of bismuth(III) was prepared by dissolving guaranteed reagent grade bismuth(III) nitrate in a small amount of concentrated nitric acid diluted with distilled water. The bismuth(III) concentration was determined by complexometric titration using Xylenol Orange as an indicator. This solution was diluted as required.

Hafnium Solution: Hafnium chloride (Nakarai Chemicals Co.) was dissolved in distilled water. For removing chloride ion, hafnium hydroxide was precipitated by adding aqueous ammonia $(1+1)$ to the solution, filtered with a $3 \mathrm{G} 4$ glass filter, and washed with distilled water. Then, a solution containing about $5 \mathrm{mg} \mathrm{cm}^{-3}$ of hafnium was prepared by dissolving this precipitate with a small amount of concentrated nitric acid and diluting with distilled water. The hafnium concentration was determined by complexometric back titration with a standard thorium solution using Xylenol Orange as an indicator.

All of the other reagents used were of guaranteed reagent grade. 
Table 1. Operating Conditions for the Atomic Absorption Spectrometer

\begin{tabular}{ll}
\hline Analytical wavelength & $223.1 \mathrm{~nm}$ \\
Lamp current & $12.5 \mathrm{~mA}$ \\
Slit width & No.3 $(2.2 \mathrm{~nm})$ \\
Argon flow-rate & $3 \mathrm{dm}^{3} \mathrm{~min}^{-1}$ \\
$\quad$ Sheath gas & $0 \mathrm{~cm}^{3} \mathrm{~min}^{-1}$ \\
Carrier gas & $10 \mathrm{~mm}^{3}$ \\
Injection volume & Uncoated tube type \\
Cuvette & graphite furnace \\
& $24 \mathrm{~A}\left(\mathrm{ca} .170^{\circ} \mathrm{C}\right), 45 \mathrm{~s}$ \\
Drying conditions & $92 \mathrm{~A}\left(\mathrm{ca} .940^{\circ} \mathrm{C}\right), 40 \mathrm{~s}$ \\
Ashing conditions & $310 \mathrm{~A}\left(\mathrm{ca} .2830^{\circ} \mathrm{C}\right), 5 \mathrm{~s}$ \\
\hline Atomizing conditions & \\
\hline
\end{tabular}

Recommended Procedure. A solution containing $20 \mathrm{mg}$ of hafnium is added to a sample solution $\left(50-400 \mathrm{~cm}^{3}\right)$ containing $0.05-3 \mu \mathrm{g}$ of bismuth(III) and the $\mathrm{pH}$ of the solution is adjusted to about 9.5 with aqueous ammonia $(1+1)$. After the precipitate has been allowed to settle, the solution is filtered by suction using a $3 \mathrm{G} 4$ glass filter. The obtained precipitate is washed with a small amount of aqueous ammonia ( $\mathrm{pH}$ about 9.5) and dissolved with $1 \mathrm{~cm}^{3}$ of concentrated nitric acid. The solution is diluted to 25 $\mathrm{cm}^{3}$ with distilled water; then the atomic absorbance of bismuth(III) is measured under the operating conditions shown in Table 1. The blank is also taken through the same procedure, using distilled water instead of a sample solution.

\section{Results and Discussion}

Effect of pH on Coprecipitation. The effect of the $\mathrm{pH}$ on coprecipitation with hafnium hydroxide was studied with a solution (about $50 \mathrm{~cm}^{3}$ ) containing $1 \mu \mathrm{g}$ of bismuth(III). The results are shown in Fig. 1. Almost $100 \%$ recoveries were obtained over the $\mathrm{pH}$ range 5.8-11.2. Therefore, the $\mathrm{pH}$ of the solution was adjusted to about 9.5 with aqueous ammonia $(1+1)$ in further experiments.

Effect of Amount of Coprecipitant on Coprecipitation. The necessary amount of hafnium for the coprecipitation was examined with a sample solution $\left(50-400 \mathrm{~cm}^{3}\right)$ containing $1 \mu \mathrm{g}$ of bismuth(III), according to the recommended procedure. More than $2.5 \mathrm{mg}$ of hafnium should be added to $100 \mathrm{~cm}^{3}$ of

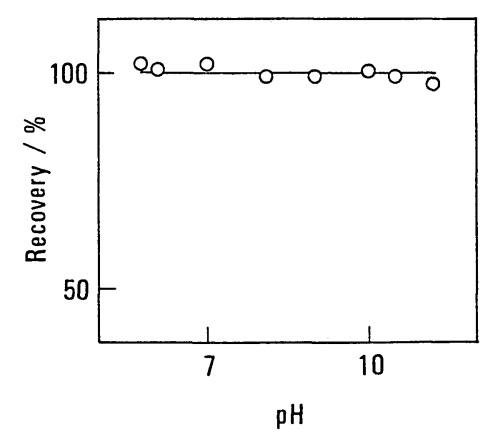

Fig. 1. Effect of $\mathrm{pH}$ on bismuth(III) recovery. Bi(III): $1 \mu \mathrm{g} / 25 \mathrm{~cm}^{3}$, Hf: $10 \mathrm{mg} / 25 \mathrm{~cm}^{3}$. solution for a quantitative collection. As the volume of sample solution increases, however, the necessary amount of hafnium was increased to $20 \mathrm{mg}$ of hafnium in $400 \mathrm{~cm}^{3}$ of sample solution. The presence of hafnium did not affect the determination of bismuth(III), and the peak heights of bismuth(III) were almost constant over the range $2.5-50 \mathrm{mg}$ of hafnium in $25 \mathrm{~cm}^{3}$.

Effect of Standing Time of Precipitate. The recovery of bismuth(III) reached almost $100 \%$ for a few minutes after the formation of hafnium hydroxide and remained unchanged upon standing for $6 \mathrm{~h}$. Therefore, the standing time was left out of consideration and the precipitate was filtered after some settlement had occurred.

Dissolution of Hafnium Hydroxide. Hafnium hydroxide dissolves easily in common concentrated mineral acids, except sulfuric acid.14) In this work, the determination of bismuth(III) in silver is one of the purposes; thus, nitric acid is used for the dissolution of hafnium hydroxide in order to avoid the formation of silver chloride. The effect of the nitric acid concentration on the atomic absorbance of bismuth(III) was examined with a solution containing $1.25 \mu \mathrm{g}$ of bismuth(III). As the amount of nitric acid increased, the absorbance gradually decreased within the range $0-5 \mathrm{~cm}^{3}$ of concentrated nitric acid. In the presence of $5 \mathrm{~cm}^{3}$ of nitric acid the absorbance was about $30 \%$ lower than that in the absence of acid. In these experiments $1 \mathrm{~cm}^{3}$ of concentrated nitric acid was used.

Optimum Instrumental Parameters. The optimum operating conditions for the determination of bismuth(III) by atomic absorption spectrometry are summarized in Table 1. They were examined with a solution containing $80 \mathrm{ng} \mathrm{cm}-3$ of bismuth(III), 0.8 $\mathrm{mg} \mathrm{cm} \mathrm{cm}^{-3}$ of hafnium, and $0.6 \mathrm{~mol} \mathrm{~cm}^{-3}$ of nitric acid. The peak height of bismuth(III) became higher with an increase in the drying current from 19.8 to $31.8 \mathrm{~A}$; it remained nearly constant above $23 \mathrm{~A}$. During the ashing stage, the peak height of bismuth(III) increased with an increase in the heating current, and reached a maximum at $90-105 \mathrm{~A}$. During the atomizing stage, the maximum peak height was obtained at $310 \mathrm{~A}$, the highest current obtainable in this apparatus. With regard to the effect of the heating time during each stage, a drying time of $30-90 \mathrm{~s}$, an ashing time of $20-$ $60 \mathrm{~s}$, and an atomizing time of $2.5-7.5 \mathrm{~s}$ gave almost constant absorbances.

Calibration Curve. A straight line passing through the origin was obtained over the concentration range $0.05-3 \mu \mathrm{g}$ of bismuth(III) in $25 \mathrm{~cm}^{3}$ using the recommended procedure. The relative standard deviation was $1.41 \%$ for $1 \mu \mathrm{g}$ of bismuth(III) in $100 \mathrm{~cm}^{3}$ of sample solution (five determinations) and the detection limit (signal to noise ratio of two) of this method was $40 \mathrm{ng}$ of bismuth(III) in $400 \mathrm{~cm}^{3}$ of initial sample solution. 
Effect of Foreign Ions. The effect of 25 foreign ions on the determination of $1 \mu \mathrm{g}$ of bismuth(III) was examined by the recommended procedure. According to the results shown in Table 2, large amounts of sodium, potassium, magnesium, and calcium did not interfere with the determination of bismuth(III). Other ions, except for copper, chromium(III), cobalt, and nickel, can also coexist at a concentration 1000fold that of bismuth(III). Copper, chromium(III), cobalt, and nickel gave negative errors on the determination of bismuth(III); however, these effects could be removed by coprecipitation above $\mathrm{pH} 11$ with aqueous ammonia. For the purpose of the determination of bismuth(III) in silver, the effect of silver was studied in detail. As shown in Fig. 2, the presence of up to $0.04 \mathrm{mg} \mathrm{cm}^{-3}$ of silver did not interfere with the determination, though the absorbance of bismuth(III) was gradually reduced along with an increase in the amount of silver. As the results show in Table 2, however, it makes it possible to remove up to $1000 \mathrm{mg}$ of silver as an ammine complex which is produced by adjusting the $\mathrm{pH}$ of the solution to above 11 with aqueous ammonia.

Determination of Bismuth(III) in Silver. Based on the above results, bismuth(III) in commercial metal silver was determined. The procedure for the determination is as follows. An adequate amount of metal silver is taken in such a manner that $0.05-3 \mu \mathrm{g}$ of bismuth(III) is contained in it, and is dissolved in a small amount of concentrated nitric acid by heating. The solution is diluted to $40-100 \mathrm{~cm}^{3}$ with distilled

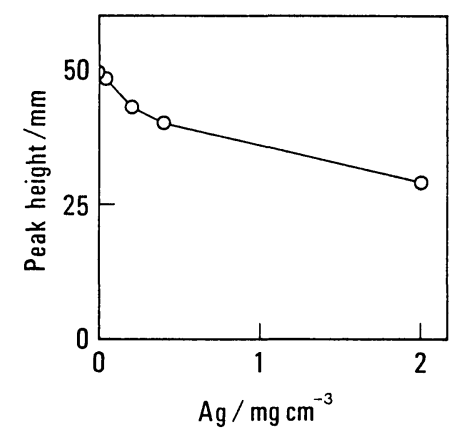

Fig. 2. Effect of amount of silver on bismuth(III) peak height.

Bi(III): $40 \mathrm{ng} \mathrm{cm}^{-3}$, Hf: $0.4 \mathrm{mg} \mathrm{cm}^{-3}$. water and $10 \mathrm{mg}$ of hafnium is added to it. An aqueous ammonia $(1+1)$ is then added to the solution until the precipitate of silver oxide is dissolved. After the precipitate of hafnium hydroxide has settled, the solution is filtered by suction using a 3G4 glass filter. The obtained precipitate is washed with a small amount of aqueous ammonia ( $\mathrm{pH}$ about 9.5) and dissolved with $1 \mathrm{~cm}^{3}$ of concentrated nitric acid. The solution is diluted to $25 \mathrm{~cm}^{3}$ with distilled water; then, the atomic absorbance of bismuth(III) is measured under the operating conditions shown in Table 1.

Table 2. Effect of Foreign Ions on the Determination of $1 \mu \mathrm{g}$ of Bismuth(III) in about $50 \mathrm{~cm}^{3}$ of Water

\begin{tabular}{|c|c|c|c|c|c|}
\hline \multirow{2}{*}{ Ion } & $\begin{array}{c}\text { Amount } \\
\text { added }\end{array}$ & $\begin{array}{l}\mathrm{Bi}(\mathrm{III}) \\
\text { found }\end{array}$ & \multirow{2}{*}{ Ion } & $\begin{array}{l}\text { Amount } \\
\text { added }\end{array}$ & $\begin{array}{l}\mathrm{Bi}(\mathrm{III}) \\
\text { found }\end{array}$ \\
\hline & $\mathrm{mg}$ & $\mu \mathrm{g}$ & & $\mathrm{mg}$ & $\mu g$ \\
\hline $\mathrm{Li}^{+}$ & 1 & 0.98 & $\mathrm{La}^{3+}$ & 1 & 1.00 \\
\hline $\mathrm{Na}^{+}$ & 50 & 0.98 & $\mathrm{Th}^{4+}$ & 1 & 0.99 \\
\hline $\mathbf{K}^{+}$ & 20 & 0.96 & $\mathrm{Cr}^{3+}$ & 0.1 & 0.89 \\
\hline $\mathrm{Mg}^{2+}$ & 6 & 0.97 & $\mathrm{Cr}^{3+\mathrm{a})}$ & 0.5 & 1.00 \\
\hline $\mathrm{Ca}^{2+}$ & 6 & 0.98 & $\mathrm{Mo}(\mathrm{VI})$ & 1 & 1.00 \\
\hline $\mathrm{Sr}^{2+}$ & 1 & 0.98 & W(VI) & 1 & 0.99 \\
\hline $\mathrm{Ba}^{2+}$ & 1 & 0.98 & $\mathrm{Fe}^{3+}$ & 1 & 1.02 \\
\hline $\mathrm{Al}^{3+}$ & 1 & 1.01 & $\mathrm{Co}^{2+}$ & 1 & 0.91 \\
\hline $\mathrm{Ga}^{3+}$ & 1 & 1.00 & $\mathrm{Co}^{2+\mathrm{a})}$ & 1 & 1.02 \\
\hline $\operatorname{In}^{3+}$ & 1 & 1.02 & $\mathrm{Ni}^{2+}$ & 1 & 0.94 \\
\hline $\mathrm{Sn}^{4+}$ & 1 & 0.97 & $\mathrm{Ni}^{2+\mathrm{a})}$ & 1 & 0.99 \\
\hline $\mathrm{Pb}^{2+}$ & 1 & 1.00 & & & \\
\hline $\mathrm{Sb}^{3+}$ & 1 & 1.01 & $\mathrm{Ag}^{+\mathrm{a})}$ & 50 & 1.00 \\
\hline $\mathrm{Cu}^{2+}$ & 1 & 0.90 & $\mathrm{Ag}^{+\mathrm{a})}$ & 100 & 1.00 \\
\hline $\mathrm{Cu}^{2+\mathrm{a})}$ & 1 & 1.01 & $\mathrm{Ag}^{+\mathrm{a})}$ & 500 & 0.96 \\
\hline $\mathrm{Zn}^{2+}$ & 1 & 0.97 & $\mathrm{Ag}^{+\mathrm{a})}$ & 1000 & 0.96 \\
\hline $\mathrm{Cd}^{2+}$ & 1 & 0.97 & & & \\
\hline
\end{tabular}

a) Coprecipitation was carried out at $\mathrm{pH}$ 11.2.

Table 3. Results of the Determination of Bismuth(III) in Silver ${ }^{\text {a }}$

\begin{tabular}{ccccc}
\hline & $\begin{array}{c}\text { Silver } \\
\text { taken }\end{array}$ & & \multicolumn{2}{c}{$\mathrm{Bi}(\mathrm{III})$ found $/ \mu \mathrm{g}$} \\
\cline { 5 - 5 } \cline { 4 - 5 } Sample No. & $\mathrm{mg}$ & & $\begin{array}{c}\text { Calibration } \\
\text { method }\end{array}$ & $\begin{array}{c}\text { Standard } \\
\text { addition } \\
\text { method }\end{array}$ \\
\hline 1 & 500 & 0.21 & 0.24 \\
2 & 500 & & 0.21 & 0.22 \\
3 & 500 & 0.20 & 0.20 \\
4 & 500 & 0.20 & 0.21 \\
\hline
\end{tabular}

a) Commercial metal silver (purity: $99.99 \%$ ) was used.

Table 4. Recoveries of Bismuth(III) from Spiked Water Samples

\begin{tabular}{|c|c|c|c|c|c|}
\hline \multirow{3}{*}{ Sample } & \multirow{2}{*}{$\begin{array}{l}\text { Sample } \\
\text { volume }\end{array}$} & \multicolumn{2}{|c|}{$\mathrm{Bi}(\mathrm{III})$ added(0.05 $\mu \mathrm{g})$} & \multicolumn{2}{|c|}{$\operatorname{Bi}(\mathrm{III})$ added( $(1 \mu \mathrm{g})$} \\
\hline & & $\mathrm{Bi}(\mathrm{III})$ found & $\mathrm{RSD}^{\mathrm{bl}}$ & $\mathrm{Bi}$ (III) found & $\mathrm{RSD}^{\mathrm{b})}$ \\
\hline & $\mathrm{cm}^{3}$ & $\mu g^{a)}$ & $\%$ & $\mu \mathrm{g}^{\mathrm{a})}$ & $\%$ \\
\hline Distilled water & 400 & 0.052 & 10.41 & 1.00 & 1.73 \\
\hline Sea water & 400 & 0.055 & 7.04 & 0.99 & 5.71 \\
\hline River water & 400 & 0.054 & 8.52 & 0.99 & 1.28 \\
\hline
\end{tabular}

a) The recoveries obtained are the average of four replicate determinations. b) Relative standard deviation. 
The blank is also taken through the same procedure, using distilled water instead of a sample solution.

As shown in Table 3 , the results of analyses obtained using the calibration method and the standard addition method were in good agreement with each other.

Recovery of Bismuth(III) from Spiked Water Samples. According to the recommended procedure, the recoveries of bismuth(III) from river and sea water samples spiked with bismuth(III) were examined. The samples were filtered through a Toyo Roshi TM$2 \mathrm{p}$ membrane filter (pore size $0.4 \mu \mathrm{m}$ ) as soon as possible after sampling, and adjusted to about $\mathrm{pH} 2$ with concentrated nitric acid. The obtained results are shown in Table 4 . From these results, it seems that this method is also applicable to analyses of these water samples.

\section{References}

1) A. Sato and N. Saitoh, Bunseki Kagaku, 26, 747 (1977).

2) M. Malusecka and H. Jedrzejewska, Chemia Analit., 21, 575 (1976); Anal. Abstr., 32, 2B45 (1977).

3) W. Yoshimura, Bunseki Kagaku, 28, 621 (1979).

4) S. Nakashima and M. Yagi, Bunseki Kagaku, 31, E.431 (1982).

5) Y. Harada, N. Kurata, and Y. Goto, Bunseki Kagaku,
33, 71 (1984).

6) K. Itsuki and M. Nagao, Bunseki Kagaku, 8, 800 (1959).

7) K. Itsuki, B. Kobayashi, and K. Nishino, Bunseki Kagaku, 8, 804 (1959).

8) K. Kato, Bunseki Kagaku, 29, 94 (1980).

9) M. Ishibashi, T. Fujinaga, and M. Sato, Bunseki Kagaku, 5, 77 (1956).

10) M. Ishibashi, T. Nagai, T. Fujinaga, and W. Funasaka, Bunseki Kagaku, 7, 553 (1958).

11) M. Ishibashi, T. Nagai, T. Fujinaga, and W. Funasaka, Bunseki Kagaku, 8, 107 (1959).

12) H. Okochi and E. Sudo, Bunseki Kagaku, 22, 431 (1973).

13) S. Ito, T. Matsuda, and T. Nagai, Bunseki Kagaku, 29, 655 (1980).

14) J. Ueda and N. Yamazaki, Bull. Chem. Soc. Jpn., 59, 1845 (1986).

15) J. Ueda and N. Yamazaki, Analyst, 112, 283 (1987).

16) J. Ueda and T. Kitadani, Analyst, 113, 581 (1988).

17) J. Ueda and C. Mizui, Anal. Sci., 4, 417 (1988).

18) J. Ueda, K. Miyanaga, and T. C. Rains, J. Anal. At. Spectrom., 3, 1031 (1988).

19) S. Fujiwara, "Korutofu Bunsekikagaku II," Hirokawa Pub. Co., Tokyo (1975), p. 300.

20) V. Hudnik, S. Gomiscek, and B. Gorenc, Anal. Chim. Acta, 98, 45 (1978).

21) J. Ueda and C. Kita, Bull. Chem. Soc. Jpn., 58, 1900 (1985). 